\title{
Radiative properties of aerosols in Saharan dust outbreaks using ground-based and satellite data: Applications to radiative forcing
}

\author{
Juan P. Díaz, Francisco J. Expósito, Carlos J. Torres, and Félix Herrera \\ Department of Physics, University of La Laguna, Santa Cruz de Tenerife, Canary Islands, Spain \\ Joseph M. Prospero \\ Rosenstiel School of Marine and Atmospheric Science, Unıversity of Miami, Miami, Florida
}

\section{María C. Romero}

Instituto Nacional de Meteorologia, Izaña GAW Observatory, Santa Cruz de Tenerife, Canary Islands, Spain

\begin{abstract}
We report on measurements of atmospheric transmission $\left(\mathrm{AT}_{T}\right)$ and aerosol optical depth $\left(\mathrm{AOD}_{T}\right)$ made at three wavelengths $(368,500$, and $778 \mathrm{~nm})$ with a spectroradiometer placed on Tenerife $\left(28.5^{\circ} \mathrm{N}, 16.3^{\circ} \mathrm{W}\right)$, Canary Islands. Using the National Oceanic and Atmospheric Administration (NOAA) advanced very high resolution radiometer (AVHRR) channel 1, we also measured the aerosol optical depth $\left(\mathrm{AOD}_{S}\right)$ and albedo over a region of the North Atlantic Ocean extending from $15^{\circ}-35^{\circ} \mathrm{N}$ to $12^{\circ}-25^{\circ} \mathrm{W}$. We observe large changes in $\mathrm{AT}_{T}$ and $\mathrm{AOD}_{T}$ when dust outbreaks pass over this region. Using all these data, we derive the asymmetry factor $(g)$, the single-scattering albedo $(\omega)$, and the local mean $\mathrm{AOD}_{T}$ and we compute the direct radiative forcing $\Delta F$ attributable to mineral dust. The local radiative forcing obtained is over the ocean $\Delta F=-9.7 \mathrm{~W} / \mathrm{m}^{2}$ and for the land $\Delta F=-4.5 \mathrm{~W} / \mathrm{m}^{2}$ with an error of $\pm 25 \%$. Extending these results to global-scale averages, we obtain values of $\Delta F$ of $-1.22 \mathrm{~W} / \mathrm{m}^{2}$ over the ocean and $-0.57 \mathrm{~W} / \mathrm{m}^{2}$ over land. The forcings attributable to dust are comparable in magnitude to those reported in the literature for anthropogenic sulphate and for biomass burning aerosols.
\end{abstract}

\section{Introduction}

Recent works have shown the importance of aerosols as a climate-forcing agent. Aerosols can affect climate both directly, by radiation scattering and absorption, and indirectly, by effecting changes in the cloud droplet concentration and size distribution. Early studies have focused on the importance of the aerosols from anthropogenic sources, e.g., non-sea-salt sulphate (nss $\mathrm{SO}_{4}^{-}$) and aerosols from biomass burning. Model-derived estimates of direct radiative forcing $(\Delta \mathrm{F})$ yield global-scale values as great as $\Delta \mathrm{F}=-1$ to $-2 \mathrm{~W} / \mathrm{m}^{2}$ [Charlson et al., 1992; Kiehl and Briegleb, 1993; Taylor and Penner, 1994; Chylek and Wong, 1995], values comparable in magnitude to the positive forcing attributed to greenhouse gases [Charlson et al., 1992]. Until recently, there has been little interest in the role of mineral dust in climate forcing. However, recent field and theoretical measurements [Li et al., 1996; Díaz et al., 2000] suggest that the mineral dust could have a large effect on the radiative properties of the atmosphere in many ocean regions where mineral dust is the dominant aerosol constituent. Modeling studies indicate that the direct radiative forcing by mineral dust could be significant on a global scale and dominant on regional scales [Tegen et al., 1996; Sokolik and Toon, 1996; Andreae, 1996].

The principal sources of mineral dust aerosol are soils in arid regions [Pinker et al., 1994; Swap et al., 1996; Husar et al.,

Copyright 2001 by the American Geophysical Union.

Paper number 2001JD900020.

0148-0227/01/2001JD900020\$09.00
1997; Moulin et al., 1997a, 1997b]. Dust derived from arid regions is clearly visible in various satellite systems such as Meteosat and NOAA AVHRR [Andreae, 1996; Swap et al., 1996; Husar et al., 1997; Nakajima and Hirigushi, 1997; Moulin et al., 1997a, 1997b]. The seasonal distribution of AOD over the oceans as measured by NOAA AVHRR shows well-defined patterns that have a plume-like character [Husar et al., 1997]; the largest and most persistent "plumes" and the highest AOD values are associated with transport from continental arid regions. The TOMS absorbing aerosol product [Herman et al., 1997], which is largely responsive to mineral dust and biomass burning sources, shows similar plume-like patterns. These various lines of evidence clearly show that on a global scale, the dust plumes from sources in North Africa are the most prominent, the most persistent, and cover the largest ocean areas.

To assess the impact of aerosols on climate, it is necessary to have a complete knowledge of the aerosol optical properties on a global scale. This requires the use of satellite methods. To this end it is necessary to relate the satellite-sensed products to ground-based measurements made with conventional radiation instrumentation [Expósito et al., 1995]. The work, which we present here, was carried out on Tenerife, Canary Islands $\left(26^{\circ}-28^{\circ} \mathrm{N}, 15^{\circ}-17^{\circ} \mathrm{W}\right)$. This region is ideally suited for the study of the radiative effects of dust because it experiences frequent Saharan dust events, especially during the summer and early fall [Arimoto et al., 1995; Prospero, 1996a, 1996b; Maring et al., 2000]. The occurrence of a Saharan dust event in the islands is readily apparent, at the simplest level, by the occurrence of a dense haze that can reduce visibility to a few kilometers. 
Although dust transport to the Canaries can take place in the marine boundary layer (MBL) from sources along the northwest coast of Africa [Bergametti et al., 1989], the main transport occurs above the MBL in a layer (the Saharan air layer (SAL)) which typically reaches to $5-6 \mathrm{~km}$ in this region [Karyampudi et al., 1999; Westphal et al., 1988]; the dust concentrations in the SAL are usually many times greater than in the underlying MBL. The chemical and physical properties of the aerosols over the ocean lying off the west coast of Africa have been firmly established in a series of long-term aerosol measurements [Arimoto et al., 1995; Chiapello et al., 1995; Chiapello, 1996; Bergametti et al., 1989, Sancho et al., 1992; Prospero, 1996a, 1996b; Husar et al., 1997; Maring et al., 2000]. These studies clearly show that tropospheric aerosol content is strongly dominated by soil dust transported out of North Africa [Prospero, 1996a] and that the temporal and spatial trend in aerosol concentrations are consistent with satellite measurements of AOD [Husar et al., 1997].

In our study we use data obtained with ground-based radiation sensors on Tenerife and with the NOAA AVHRR satellite sensor during the period from June 1 to August 31, 1994 (natural days 152-243). During this time, AVHRR recorded several strong dust outbreaks that emerged from the west coast of North Africa and passed over the Canary Islands; coincident with these events, increased dust concentrations were measured at ground stations located on Tenerife. In this work we focus on AVHRR data obtained over the region between $15^{\circ}-35^{\circ} \mathrm{N}$ and $12^{\circ}-25^{\circ} \mathrm{W}$.

\section{Experimental Methods}

\subsection{Ground-Based Data}

The AOD is computed using the Lambert-Beer-Bouguer law:

$$
L(\lambda)=L_{0}(\lambda) \exp \left(-\left[\tau_{R}+\tau_{\mathrm{abs}}+\tau_{A}\right] \delta\right)
$$

where $L_{0}(\lambda)$ and $L(\lambda)$ are the monochromatic intensities of the incident and transmitted radiation, $\tau_{R}$ is Rayleigh scattering coefficient, $\tau_{\text {abs }}$ is the absorption coefficient, $\tau_{A}$ is the $\mathrm{AOD}_{T}$, and $\delta$ is the air mass (the path length through the atmosphere

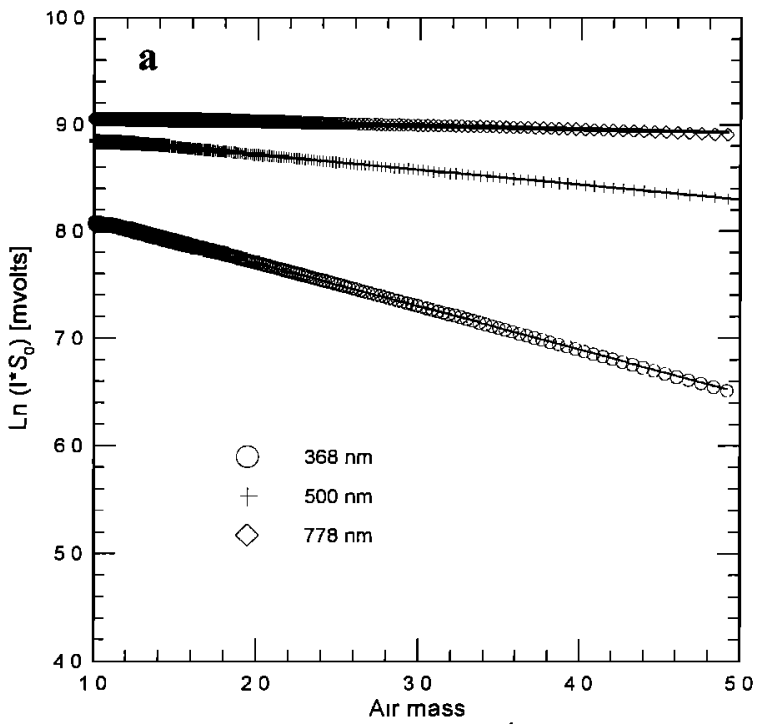

expressed as a multiple of the atmospheric thickness in the vertical). The coefficients $\tau_{R}$ and $\delta$ are calculated [Iqbal, 1983]:

$$
\begin{aligned}
\delta & =\left[\cos \theta_{0}+0.15\left(93.885-\theta_{0}\right)^{-1.263}\right]^{-1}, \\
\tau_{R} & =0.00838 \lambda^{-(3.916+0.074 \lambda+0.05 / \lambda)},
\end{aligned}
$$

with $\theta_{0}$ the Sun zenith angle (in degrees) and $\lambda$ is the wavelength in micrometers. We have used the factor $P(\mathrm{mbar}) / 1013.25$ [Igbal, 1983] to correct for the altitude, where $P$ is the pressure at the measurement station. To correct for ozone absorption in equation (1) we use column ozone concentrations obtained by a Brewer instrument located on Tenerife, at Izaña Global Atmospheric Watch (GAW) Observatory (IZO) $\left(28^{\circ} 18^{\prime} \mathrm{N}, 16^{\circ} 29^{\prime} \mathrm{W}\right)$.

The ground-based instrument used to measure $L(\lambda)$ in equation (1) is a PMOD/WRC Sun photometer mounted on a Sun tracker with a photocell autocorrection system, which guarantees perfect alignment with the Sun all day. An observer checks its operation daily. The instrument uses interference filters at 368,500 , and $778 \mathrm{~nm}$ (full width at half maximum (FWHM) of $5 \mathrm{~nm}$ ) and has a $2.6^{\circ}$ field of view (FOV). The rear baffles, filters, and silicon detectors are housed in a temperature-controlled aluminium block maintained at $30^{\circ} \mathrm{C}$. The detector is a silicon photovoltaic type UV-215B. The radiance is recorded each minute. The Sun photometer is located at Izaña GAW Observatory, managed by the Instituto Nacional de Meteorología (INM), Spain; it is located on top of a mountain platform on a dorsal ridge at an altitude of $2367 \mathrm{~m}$ above sea level.

The extraterrestrial signal $L_{0}(\lambda)$ is obtained by the Langley method: the intersection of the linear fit of the natural logarithm of the $L(\lambda)$ measurements made during the course of the day plotted versus the air mass [Diaz et al., 1994]. The value of the resulting $L_{0}(\lambda)$ is acceptable when the fitted straight line has a residual standard deviation less than 0.002 . Figures $1 \mathrm{a}$ and $1 \mathrm{~b}$ shows the Langley calibration at the wavelengths of 368,500 , and $778 \mathrm{~nm}$ for two days, one where the atmospheric stability is high (Figure 1a) and another one where the stability is poor (Figure 1b). We typically obtain correlation factors greater than

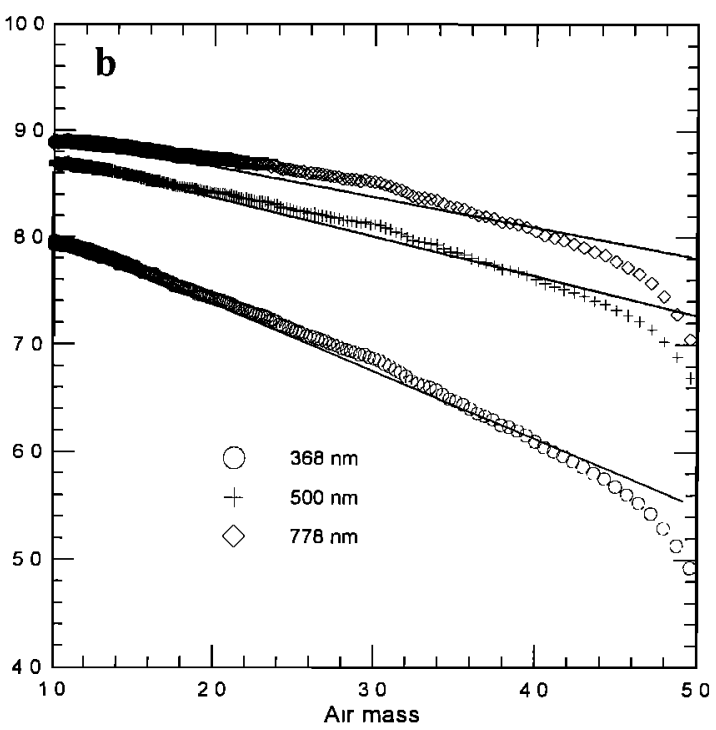

Figure 1. Examples of Langley plots: (a) Langley plot on a day with low and unvarying concentrations of aerosols (natural day 169). (b) Langley plots when dust was present and when concentrations varied during the day (natural day 186). 
0.999 and standard deviations less than 0.005 on days when aerosol concentrations are low and constant. The ordinate axis shows the intensity recorded by the PMOD multiplied by a $S_{0}$ factor, in order to correct for changes in the Sun-Earth mean distance.

We compared the results of our Langley calibrations with those obtained by the statistical procedure of Herman et al. [1981] in order to assess the precision of the computed $L_{0}(\lambda)$. The latter assumes that the deviation of the data points is due to real random variations of AOD during the course of the measurements. The results obtained with these two methods typically differ by less than $1 \%$.

The atmospheric transmission, defined as the ratio of the radiance detected by the Sun photometer to the extraterrestrial radiance $\left(\mathrm{AT}_{T}=L(\lambda) / L_{0}(\lambda)\right)$ was measured at 368,500 , and 778 nm.

The principal sources of uncertainty in $\mathrm{AOD}_{T}$ measured at the ground are variability in the air mass; the accurate characterization of the filters' spectral characteristics; the forward scattered radiation which reaches the detector within its FOV; and the extraterrestrial signal of the Sun photometer [Russell et al., 1993; Dutton et al., 1994; Thomason et al., 1983; Reagan et al., 1986; Box and Deepak, 1979]. The air mass factor $\delta$ depends on the true solar zenith angle, on the vertical distribution of the attenuating substances (i.e., gases and aerosols), on the photometer altitude, and on the temperature profile, which determines the atmospheric refraction. Following Russell et al. [1993] and Dutton et al. [1994] the errors evaluating $\delta$ with the expression (2) can be negligible up to solar zenith angles of $70^{\circ}$.

The instrument was calibrated in 1991 and again in 1995 at the World Radiation Center, Davos, Switzerland. In both calibrations no significant changes were noted in the spectral response of the band-pass filters $2(500 \mathrm{~nm})$ and $3(778 \mathrm{~nm})$. Channel $1(368 \mathrm{~nm})$ showed a $15 \%$ decrease in sensitivity between calibrations. This degradation can be fitted by an exponential curve with a correlation coefficient of $87 \%$, and it was taken into account in computing the AOD.

Because photometers have a nonzero $\mathrm{FOV}$, the measured solar radiance includes both direct and diffuse contributions. This forward scattered light results in an underestimation of the $\mathrm{AOD}_{T}$; this effect increases with the optical depth, the FOV, the air mass and the concentrations of large particles (i.e., those that the radius, assumed to be spherical, is $\geq \lambda$ ). Dutton et al. [1994] have quantified this source of error for a PMOD radiometer (FOV $2.3^{\circ}$ ) and find that the underestimation of $\mathrm{AOD}_{T}$ is less than $7 \%$ at $380 \mathrm{~nm}$ and $4 \%$ at $778 \mathrm{~nm}$.

We compare our $\mathrm{AOD}_{T}$ data obtained by radiation measurements with nss $\mathrm{SO}_{4}^{\overline{-}}$ and mineral aerosol concentrations measurements made during the same general time period on Tenerife. One sampling site is at Izaña Observatory (IZO), which during dust outbreaks is located within the SAL; consequently, samples collected at the site should be generally representative of aerosol characteristics in the layer. The samplers only operate during the night (between roughly 20:00 and 08:00) when a downslope wind circulation is in effect; thus during the night, samples are representative of the composition of the free troposphere with little likelihood of contamination from local sources. A second sampling site is located in the MBL at Punta del Hidalgo (PDH) $\left(28^{\circ} 35^{\prime} \mathrm{N}\right.$, $16^{\circ} 20^{\prime} \mathrm{W}$ ) on the north coast of the island at the top of a light house $55 \mathrm{~m}$ above the sea surface; a strong northeast trade-wind flow is in effect most of the time at this site. Samples at Hidalgo were collected on a diel cycle.
Bulk aerosol particles are collected with high volume samplers $\left(45 \mathrm{~m}^{3} / \mathrm{h}\right)$ on Whatman-41 filters; in the marine environment the collection efficiency of Whatman-41 filters is essentially $100 \%$ for nss $\mathrm{SO}_{4}^{=}$[Pszenny et al., 1993] and dust [Savoie, 1984]. The filters are extracted with water, and the mineral dust concentration is determined by ashing the extracted filter at $500^{\circ} \mathrm{C}$ for sev, sral hours and weighing the residue.

\subsection{Satellite Sensor Algorithm}

To obtain the AODs and albedo, we used the NOAA satellite sensor data; to capture and process the data, we used a high-resolution picture transmission (HRPT) system. AVHRR channel $1(0.63 \mu \mathrm{m})$, channel $2(0.82 \mu \mathrm{m})$, and channel $4(10.76$ $\mu \mathrm{m})$ have $1.1 \mathrm{~km}$ nadir resolution [Kidwell, 1995]. The $\mathrm{AOD}_{S}$ is calculated using the upwelling radiance in channels 1 and 2 according to Durkee et al. [1986] and the albedo according to Rao and Chen [1994]. These methods can only be used over the ocean; the image pixel must be cloud-free, and the following conditions must obtain (1) satellite zenith angle $<50^{\circ}$, (2) solar zenith angle $<50^{\circ}$, (3) Sun reflection angle $>50^{\circ}$, (4) brightness temperature channel $4>0^{\circ} \mathrm{C}$, (5) channel 2 albedo $<3 \%$, (6) channel $1 /$ channel 2 ratio $>1.5$, and (7) maximum channel 2 albedo variation of the central pixel of a $3 \times 3$ pixel box with its eight neighbors $<0.25$.

Conditions 1 and 2 ensure good illumination and a good observation geometry for the satellite [Frulla et al., 1995]. With condition 3 we avoid Sun glint; condition 4 eliminates pixels that contain high clouds, and condition 5 eliminates low clouds. Finally, conditions 6 and 7 detect and reject pixels with broken cloud [Young, 1992].

The method for obtaining AOD with the AVHRR satellite $\left(\mathrm{AOD}_{s}\right)$ was tested by comparing the satellite values with those obtained with a spectroradiometer installed at the Nautical School inside the Santa Cruz harbor $\left(28.48^{\circ} \mathrm{N}, 16.24^{\circ} \mathrm{W}\right)$ on the northeast end of the island. We measured radiances at $630.0 \mathrm{~nm}$ (i.e., the center of the NOAA channel 1) using a $2 \mathrm{~nm}$ FWHM filter. To correct for ozone absorption at this wavelength, we use column ozone concentrations obtained by the Izaña GAW Observatory Brewer instrument. The satellite sensor data were taken from pixels in a cloudless area located over the sea, very close to the coastline where the radiometer was located; satellite data were averaged over a $3 \times 3$ pixel box. The ground-based measurements were collected at the same time as the satellite over passes. Data were obtained during July 1994 when AOD varied over a wide range, thus enabling us to compare the response of the instruments for a complete set of different conditions. The fit of the $\mathrm{AOD}_{s}$ versus $\mathrm{AOD}$ from ground $\left(\mathrm{AOD}_{T}\right)$ gave the straight line:

$$
\mathrm{AOD}_{S}=(0.12 \pm 0.07)+(0.95 \pm 0.16)^{*} \mathrm{AOD}_{T}
$$

Expósito et al. [1997] obtained a correlation coefficient of $91 \%$ and an estimation standard error of 0.11 . They showed that the linearized single-scattering approximation used to resolve the radiative transfer equation yields good results even for situations with high AOD values. The AOD satellite images shown in this work are not corrected by the bias error in equation (4). Because of the different sources of aerosols in the whole area shown in the satellite image we consider that this equation could be valid in a region around the ground base.

Albedo values were obtained using the Rao and Chen [1994] procedure. They have computed the degradation in the performance of the AVHRR channels 1 and 2, due mainly to the outgassing and launch-associated contamination and the 
continued exposure to the harsh space environment. These authors determined the degradation rates of the sensor using statistical procedures on the International Satellite Cloud Climatology (ISCCP) B3 data for the southeastern part of the Libyan desert $\left(21^{\circ}-23^{\circ} \mathrm{N}\right.$ latitude, $28^{\circ}-29^{\circ} \mathrm{E}$ longitude). They estimated that the relative degradation rate for the NOAA 11/AVHRR channels 1 and 2 was $1.2 \%$ and $2.0 \%$ per year, respectively, assuming that the desert site was a radiometrically stable target; they concluded that the decay of the sensors was exponential in time. The formula obtained for albedo in percent was

$$
\text { albedo [\%] }=(C-40)^{*} 0.1060 * \exp \left(0.33 * 10^{-4 *} d\right),
$$

where " $C$ " is the AVHRR measured signal on the 10 bit scale and " $d$ " is the elapsed time from the day of launch expressed in days (NOAA 11 was launched on September 24, 1988).

Both $\mathrm{AOD}_{S}$ and albedo have been obtained in the region located between the parallels $15^{\circ}-35^{\circ} \mathrm{N}$ and the longitudes $12^{\circ}-25^{\circ} \mathrm{W}$, which is the area covered by Saharan dust events [Swap et al., 1996; Stowe et al., 1997; Husar et al., 1997; Herman et al., 1997]. In this Atlantic Ocean region, on a mass basis, the dust is the principal aerosol component [Prospero, 1996a, 1996b].

\section{Atmospheric Optical Properties in Saharan Dust Outbreaks}

From a synoptic point of view the dominant meteorological situation over the subtropical Northeast Atlantic is characterized, on the surface, by a high over Azores Islands (Azores High) and relative lows over the lberian Peninsula and Morocco. Under this situation there is a general flow from the NE (i.e., a trade wind flow) and it is unlikely that Saharan dust outbreaks can reach our ground stations on Tenerife, although at times it is possible to see on satellite images dust events with plumes very close to the African coastline. In contrast, large-scale Saharan dust outbreaks usually occur under a synoptic situation where there is an anticyclone at high level (600-500 mbar) over NW Africa and where the Azores High is displaced from its normal position. Under these conditions the predominant wind directions range from easterly through southerly to westerly depending of the specific orientation of the pressure systems. During the study period both synoptic situations occurred.

The $\mathrm{AOD}_{T}, \mathrm{AT}_{T}$, and aerosol concentrations varied over a wide range during the course of the measurements. Figure 2 shows the time series of $\mathrm{AOD}_{T}$ (dots) and $\mathrm{AT}_{T}$ (solid line) for the period between natural days 150-250 with a time step of 1 min. Note that $\mathrm{AOD}_{T}$ values were relatively low and constant until about natural day 180 when they increased sharply; thereafter, $\mathrm{AOD}_{T}$ values remained quite high until about natural day 220, although there were a few periods when the $\mathrm{AOD}_{T}$ dropped to low values. After natural day $220, \mathrm{AOD}_{T}$ values remained relatively low and steady but with occasional periods of modestly increased values. The $\mathrm{AT}_{T}$ values in Figure 2 were quite variable throughout the measurement period. Some of this variability is due to the presence of cloud. Cloud effects are particularly notable before natural day 180 and after natural day 220 when decreased $\mathrm{AT}_{T}$ values are associated with gaps in the $\mathrm{AOD}_{T}$ record. To calculate $\mathrm{AOD}_{T}$, the clouds have been screened using the records of a broadband pyranometer. Nevertheless the presence of thin clouds mixed with dust is possible. A second procedure cuts the data when they are bigger than a limit value. The presence of dust in the ground station is confirmed by visual observation of an experimented observer (the Izaña station has GAW classification). The AOD above 0.8 at $365 \mathrm{~nm}$ (or 0.7 at $500 \mathrm{~nm}$, etc.) must be interpreted as clouds with dust. Comparison of the curves in Figure 2 shows that between natural days 180 and 220, periods of high $\mathrm{AOD}_{T}$ are associated with periods of decreased $\mathrm{AT}_{T}$.

Figure $3 \mathrm{a}$ and $3 \mathrm{~b}$ presents aerosol data obtained at Izaña and Punta del Hidalgo for the same time periods as shown in Figure 2; data are shown for both mineral dust and nss $\mathrm{SO}_{4}^{=}$Also shown (Figure 3.c) is plot of $\mathrm{AOD}_{T}$ at $500 \mathrm{~nm}$ to facilitate


concentration.

A number of dust episodes are evident in Figure 3 at Izaña and Punta del Hidalgo. At Izaña observatory the concentration of nss $\mathrm{SO}_{4}^{-}, \mathrm{NO}_{3}^{-}$, and $\mathrm{NH}_{4}^{+}$[Prospero, 1996a, 1996b] shows a temporal variability that tracked that of mineral dust; however, the mineral dust concentrations are, on average, an order of magnitude greater than that of all the other major aerosol species combined [Prospero, 1996a]. At Hidalgo the dust concentration was much lower than at Izaña and the temporal variability of dust and other species is very different as well. At both sites, nss $\mathrm{SO}_{4}^{-}, \mathrm{NO}_{3}^{-}$, and related species are believed to be largely derived from pollution sources in Europe. At Izaña the pollutants are transported across North Africa where they are intermixed with dust-laden air masses and subsequently carried to the North Atlantic [Prospero, 1996a, 1996b]. At Hidalgo the aerosol composition and concentration is largely attributable to direct transport over the North Atlantic from sources in Europe [Raes et al., 1997]. The difference in composition and temporal variability at these two sites illustrates the sharp separation between the transport regimes in the boundary layer and those in the free troposphere.

In Figures 2 and 3 it can be seen that in general, the time record of $\mathrm{AOD}$ measurements made on Tenerife $\left(\mathrm{AOD}_{T}\right)$ tracks that of mineral dust concentrations at Izaña. However, it should be noted that the aerosol measurements are made at Izaña only at night, during downslope wind conditions [Prospero, 1996a, 1996b]; thus the aerosol data are not truly concurrent with the radiation measurements. Also, because of other sampling protocol criteria, samples cannot be collected every night, thus leading to gaps in the aerosol data. Nonetheless, these data are consistent with our hypothesis that the radiative properties of the atmosphere during dust outbreaks are largely determined by the concentration of mineral dust in the atmosphere. This is emphasized in Figure 4, which shows $A \mathrm{D}_{T}$ and $A T_{T}$ at $500 \mathrm{~nm}$ for a typical clear day (natural day 173) and for a dusty day (natural day 186). On dust-free days, $\mathrm{AOD}_{T}$ at $500 \mathrm{~nm}$ has a quasi-constant value of about 0.05 , whereas on dusty days, $\mathrm{AOD}_{T}$ is very variable with values in the range $0.25-0.60$. The day-to-day changes in $\mathrm{AOD}_{T}$ can be associated to changing meteorological conditions. During the summer and early fall, days with low aerosol concentrations are usually associated with trajectories emanating from the central North Atlantic, typically from the middle or upper troposphere; days with high concentrations of aerosols, including dust, are attributed to trajectories emerging from North Africa [Prospero, 1996a, 1996b]. At noon on a dust-free day, $\mathrm{AT}_{T}$ can reach values of 0.85 ; values do not show much variation with time on such days. In contrast, on dusty days, $\mathrm{AT}_{T}$ has a maximum value around 0.70 and values can be quite variable apparently due to the variability in aerosol concentrations.

Figure 5 presents the computed $\mathrm{AOD}_{S}$ from NOAA AVHRR channel $1(630 \mathrm{~nm})$ for natural days $178,181,189$, and 190; the figure shows how $\mathrm{AOD}_{S}$ changes during the evolution of a dust event. The first picture is a typical dust-free day at the ground 

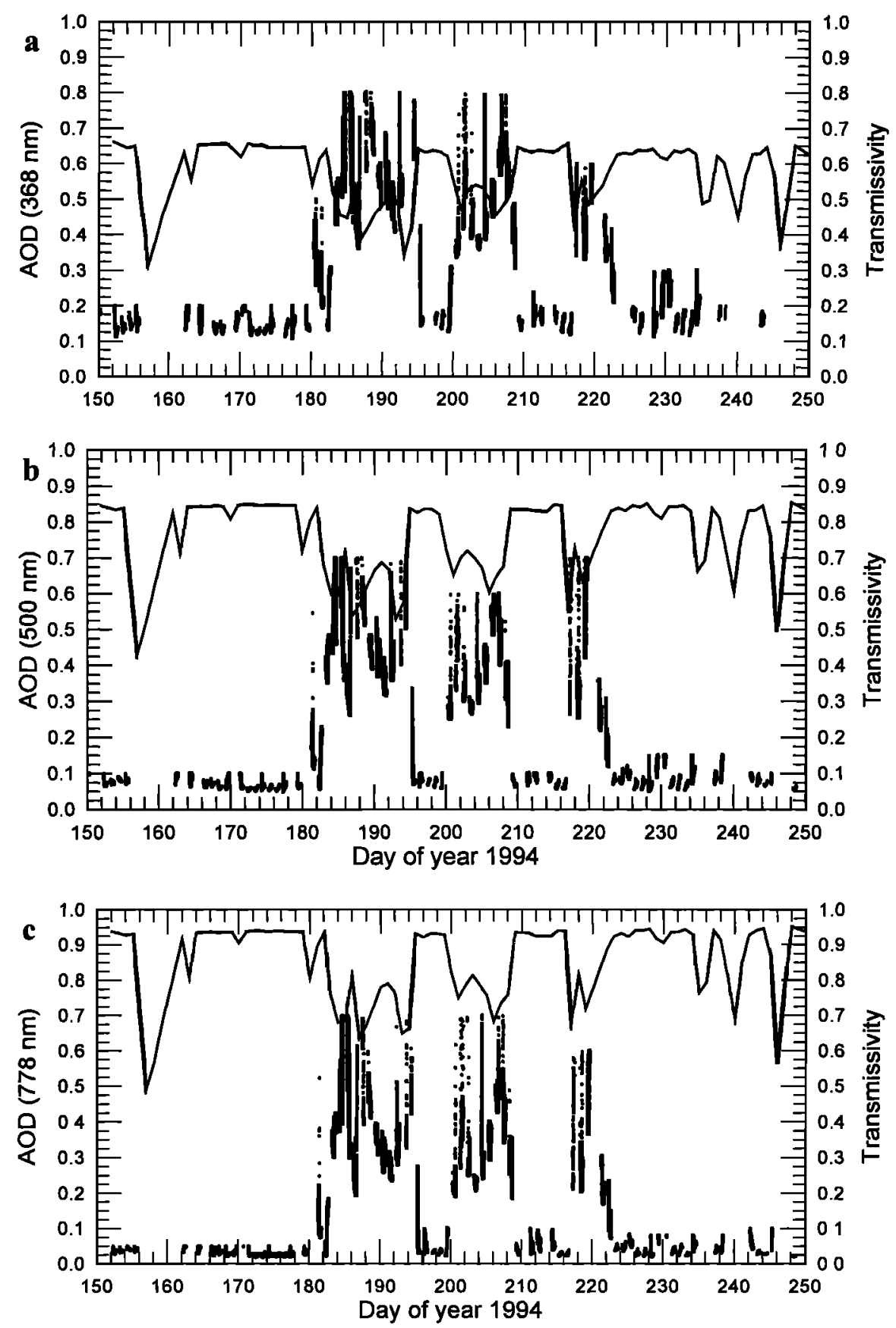

Figure 2. From top to bottom $\mathrm{AOD}_{T}$ (dots) and $\mathrm{AT}_{T}$ (solid line) versus natural day at (a) 368 , (b) 500 , and (c) $778 \mathrm{~nm}$.

stations prior to a dust outbreak over the Atlantic Ocean; the subsequent three images show the movement of the dust "plume" for the following days as it moves over the Canary Islands. On clear days (without dust) the $\mathrm{AOD}_{s}$ is generally high close to the African coastline, with maximum values of 0.4 ; in contrast, over the central ocean, values are typically less than 0.1 . The histogram of the natural day 178 image plotted in Figure 6a shows clearly the pattern described before. We can see that there are two peaks, one centered around low AOD values, 0.06 and another at about 0.22 .

In the latitude of the Canary Islands, dust outbreaks can extend over the ocean to distances of several hundred kilometers and more. When a dust outbreak emerges from the northwest coast of Africa, $\mathrm{AOD}_{S}$ values of 0.6 are measured near the coast; farther out over the ocean, values of 0.4 are common. Figure $6 \mathrm{~b}$ is the histogram of a dusty day image (Figure $5 \mathrm{c}$ ) and shows a different pattern with respect to the image histogram of the natural day 178 (clear day). The absolute maximum centered at 0.22 has increased $30 \%$, and there appears a new secondary maximum with AOD values between 0.35 and 0.4 .

Durkee et al. [1986] has determined that the aerosol particledependent terms in the radiative transfer equation are larger at red wavelengths than at near-infrared wavelengths for small aerosol particles. The spectral variation can be quantified by a simple ratio between red and near-infrared wavelengths. Thus a rough indication of the character of the aerosol size distribution 

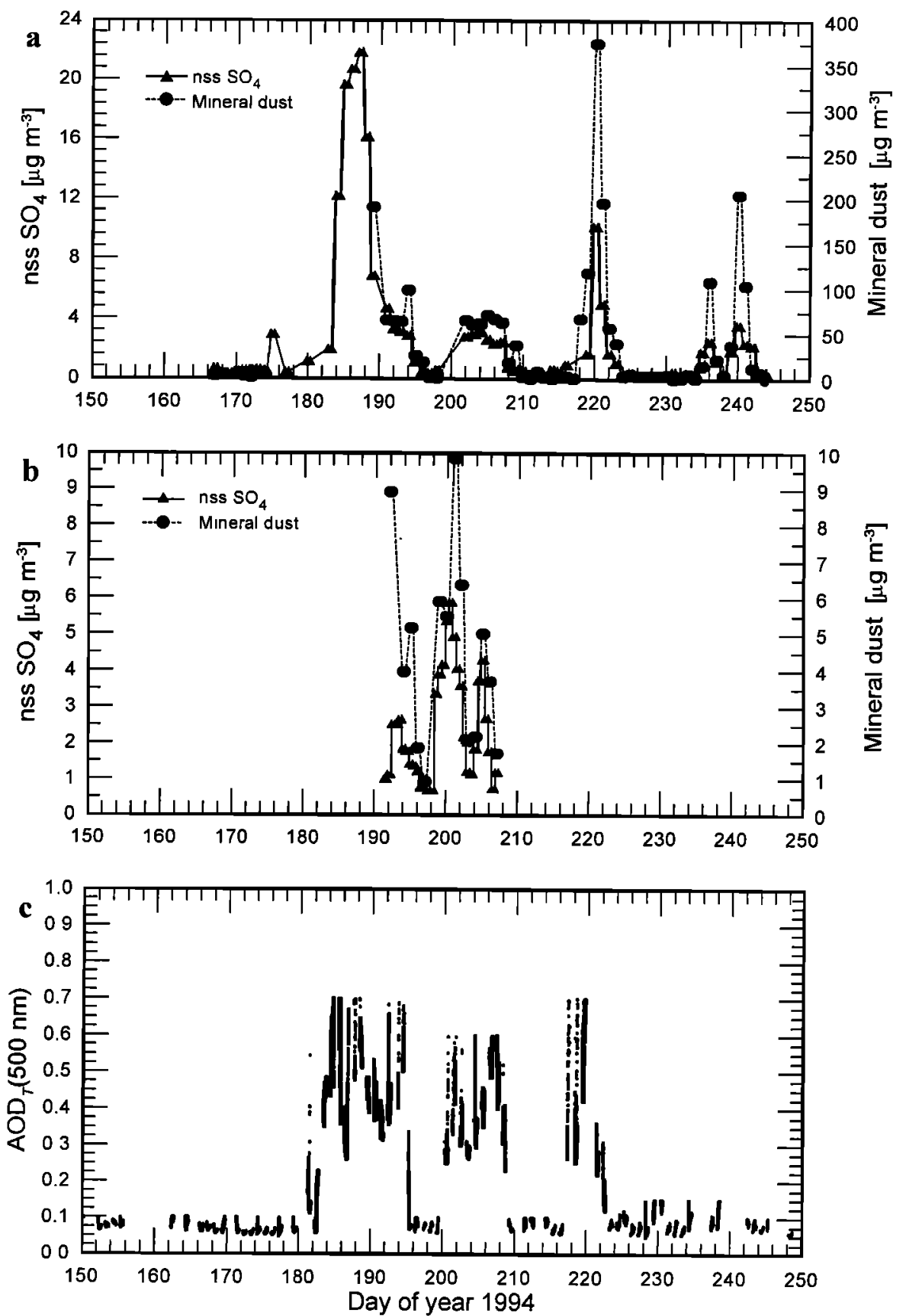

Figure 3. (a) Izaña: nss $\mathrm{SO}_{4}$ (triangle and solid line) and mineral dust (circle and dashed line) in micrograms per cubic meter versus natural day. (b) Punta del Hidalgo: nss $\mathrm{SO}_{4}$ (triangle and solid line) and mineral dust (circle and dashed line) in micrograms per cubic meter versus natural day. (c) $\mathrm{AOD}_{T}$ time series $(500 \mathrm{~nm})$ as measured at Izaña Observatory.

can be obtained by the ratio of the NOAA AVHRR channel 1 $(630 \mathrm{~nm})$ to channel $2(820 \mathrm{~nm})$ (henceforth $\left.R_{12}\right)$. Relatively large values of $R_{12}$ are generally associated with particle size distributions that are characterized by relatively higher concentrations of small particles [Frost, 1988; Laine, 1992; Porter, 1993]. We observe low $R_{12}$ values $(<2.0)$ near the coast of Africa where large particles (mineral dust aerosols) are relatively more abundant; in contrast, we typically observe values of 4.0 over the central North Atlantic Ocean where dust concentrations are low and where maritime (and perhaps pollutant) aerosols are dominant (Figure 7).
In the hypothesis of the aerosol optical depth $\tau$, follows a Junge function $\left(\tau(\lambda)=k \cdot \lambda^{-(v+1)}\right)$, the $v$ parameter can be obtained by the ground-based Sun photometer data. To investigate the power of $R_{12}$ to give information about the aerosol size distribution present in the studied zone, this parameter, which can be easily calculated, has been related with the $v$ parameter. This relation is not still clear and Ignatov et al. [1998] indicate that it can be accurately obtained only for high AOD. In Figure 8 we can see the Junge size parameter $(v)$ versus the ratio NOAA channel $1 /$ channel $2\left(R_{12}\right)$. The points shown correspond to those for which there were values for the satellite and the Sun 


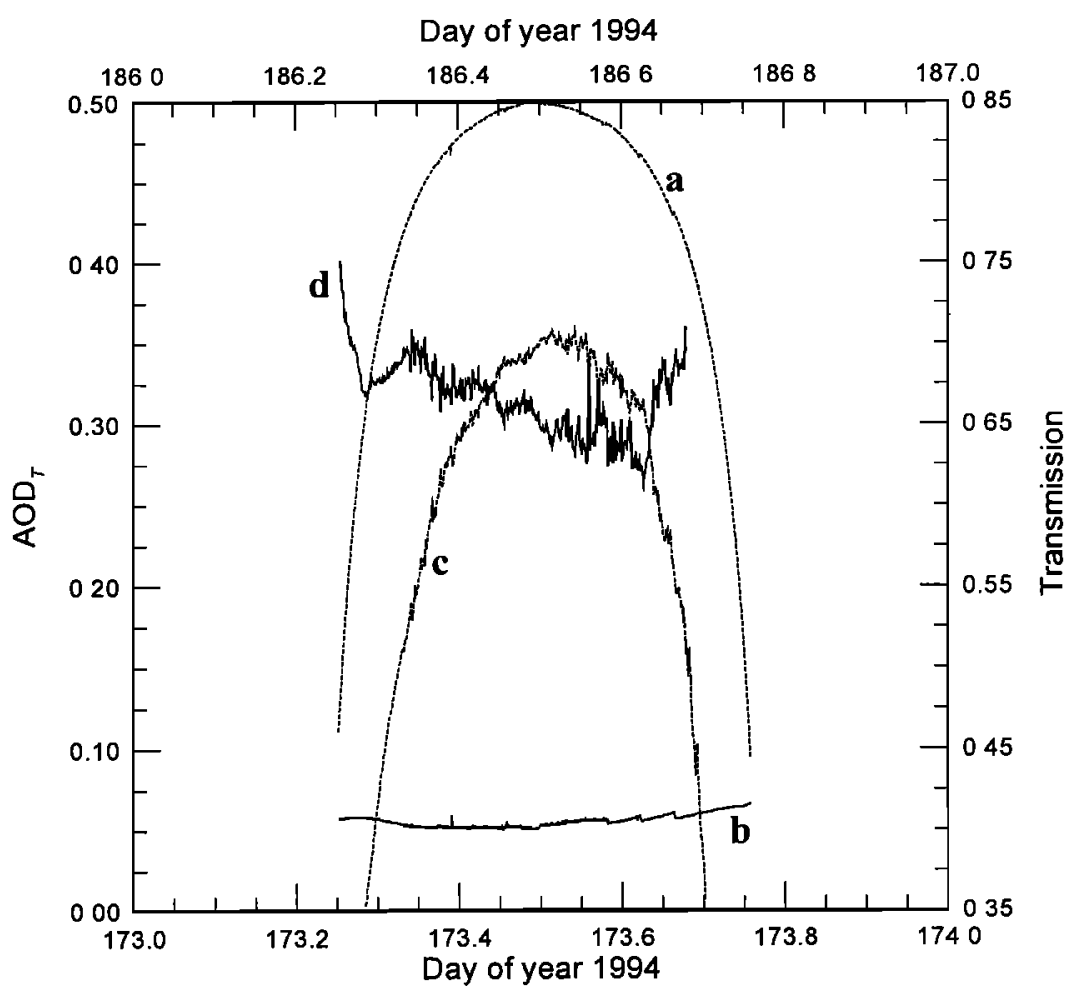

Figure 4. Day-long record of (a) $\mathrm{AT}_{T}$ and (b) $\mathrm{AOD}_{T}$ (at $500 \mathrm{~nm}$ ) for a typical clear day (natural day 173, scale at bottom of figure); (c) $\mathrm{AT}_{T}$ and (d) $\mathrm{AOD}_{T}$ for a dusty day (natural day 186, scale at top of figure).

photometer simultaneously, obtained during the period of natural days 150 to 191 . High values of the $v$ parameter suggest the predominance of small particles over the largest ones, whereas low $v$ values indicate the opposite [Tomasi et al., 1983]. In the light of this figure we can fit the data by a linear regression with equation $v=1.14^{*} R_{12}-0.15$.with a correlation factor of $R=0.93$. Thus, the $R_{12}$ parameter can be used to extract rough information about the particle size distribution in the whole satellite image.

Figure 9 shows the computed albedo from AVHRR channel 1 for two example images, one for clear day (natural day 178) and another one for a dusty day (natural day 189). On clear days the albedo has values around 3\% along the African coastline, with the highest values $(3.9 \%)$ in the region where the dust usually emerges from West Africa in the summer [Husar et al., 1997]. In contrast, to the north and farther out over the open ocean, the albedo is lower, with values around $2.4 \%$ in the Canary Islands region and around $1.7 \%$ in the central North Atlantic. On days when there is a dust outbreak, albedo values as high as $10 \%$ are observed in the dust plume over the ocean. The very high albedo values seen in a narrow band along the left edge of the image in Figure $9 \mathrm{~b}$ are not due to dust effects but rather to Sun glint caused by the relative position of the Sun and the satellite. The data included in the histograms of the images are not affected by Sun glint. Figures $6 \mathrm{c}$ and $6 \mathrm{~d}$ present the albedo frequency histograms for these two days. Note the differences in the albedo pattern for the low values (less than $3 \%$ ).

To assess the increase in upwelling radiance during dust events, we studied the variation of albedo with respect to $\mathrm{AOD}_{s}$. Using the albedo and $\mathrm{AOD}_{s}$ values from cloudless pixels in images, we obtain the relationship shown in Figure 10. Each dot shown in this figure is actually the representative of its class.
This classification has been done comparing, in an image, each pair with the rest, considering that two data pairs ( $\mathrm{AOD}_{S}$, albedo) are different if at least one of the pair component differs more than $5 \%$ with respect to the same variable of another pair. Thus each dot in Figure 10 represents a large number of image pixels and therefore is associated with a frequency of occurrence. We have plotted the representative of the classes whose frequency of occurrence is higher than a given value $(0.05 \%)$. Using this selection, we make sure that they represent more than $75 \%$ of the total number of the image pixels.

Figure 10 shows a scatterplot of albedo versus $A O_{S}$ for two different situations: (Figure 10a) for a day when the satellite image shows the absence of Saharan dust over the Atlantic Ocean (natural day 178); (Figure 10b) for a day when a dust outbreak is in the region (natural day 189). The data for the Figure $10 \mathrm{a}$ plot can be fitted by the straight line: $15.6 x+1.8$ with a correlation coefficient $r^{2}=91 \%$. The intercept, 1.8 , agrees with the typical ocean albedo value for AVHRR NOAA channel 1 for an aerosol-free atmosphere, as measured by Ignatov et al. [1995]. Using the data for a Saharan dust outbreak (Figure 10b), we obtain a fit with a second-order polynomial: $-11.2 x^{2}+22.3 x+0.9$ with a correlation coefficient of $89 \%$. The portion of this line for values of $\mathrm{AOD}_{\mathrm{S}}$ less than about 0.5 fits closely to the linear fit in Figure 10a.

\section{Estimation of Radiative Forcing}

To properly assess the direct radiative forcing of mineral dust, we have employed the approach described by Charlson et al. [1992], Penner et al. [1992], and Sokolik and Toon [1996], where the radiative forcing $\Delta F$ is given by

$$
\Delta F=-\left(S_{0} / 4\right) T^{2}(1-N)\left[\omega(1-g / 2)(1-a)^{2}-4 a(1-\omega)\right] \tau,
$$



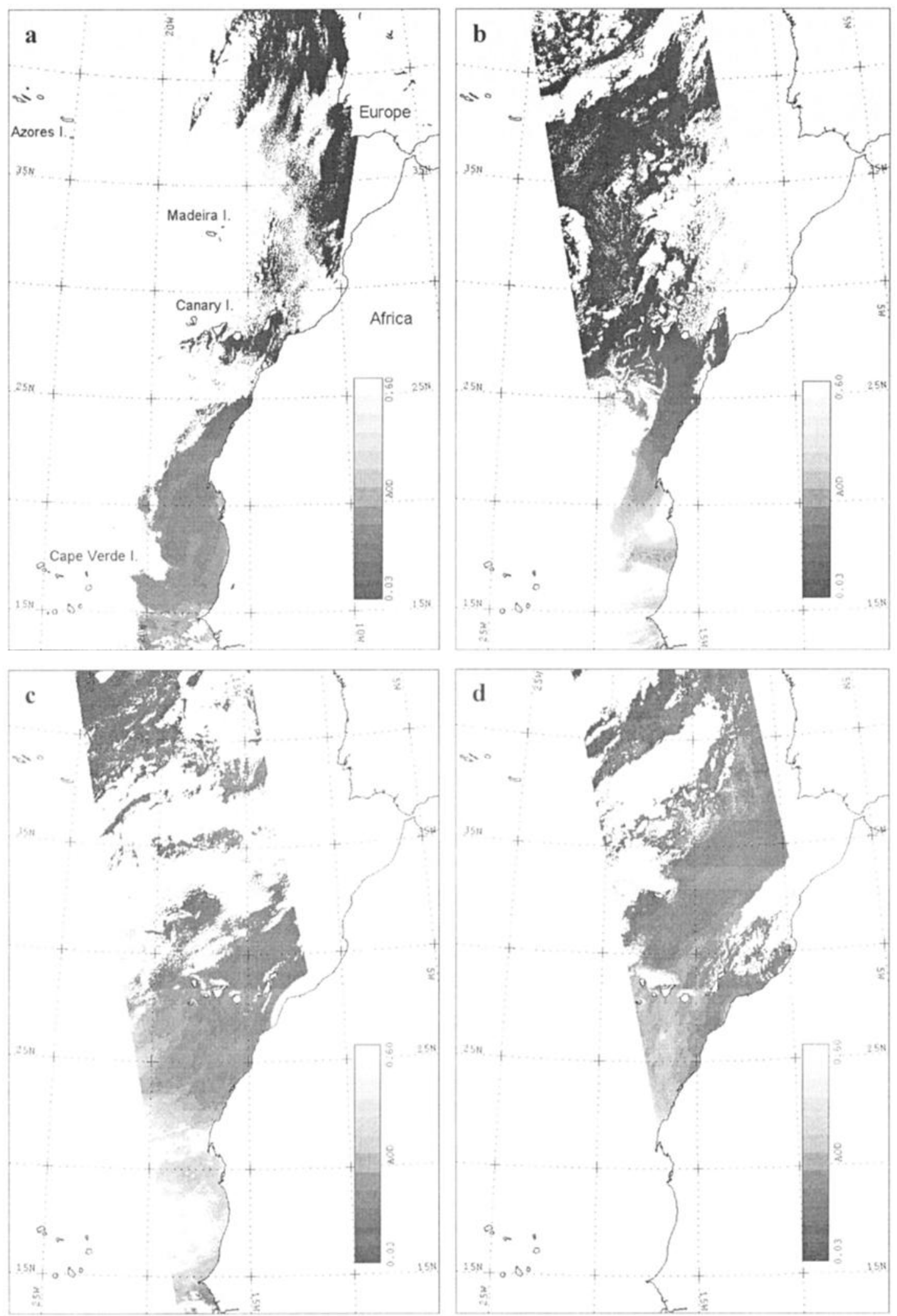

Figure 5. $\mathrm{AOD}_{s}$ for the natural days (a) 178, (b) 181, (c) 189, and (d) 190, showing an evolution of a dust episode. White dots are clouds or bad data.

where $S_{0}$ is the solar constant $\left(1,370 \mathrm{~W} / \mathrm{m}^{2}\right), T$ is the atmospheric transmission above the aerosol layer $(0.79), N$ is the cloud fraction (0.6) [Penner et al., 1992; Chylek and Wong, 1995 ], $a$ is the globally averaged surface albedo ( 0.06 over ocean and 0.22 over land) [Chylek and Wong, 1995], $\tau$ is the mean dust optical depth, $\omega$ is the aerosol single-scattering albedo, and $g$ is the asymmetry factor

We have computed the local mean dust optical depth, the asymmetry factor, and the single-scattering albedo for mineral dust using the following expressions: 

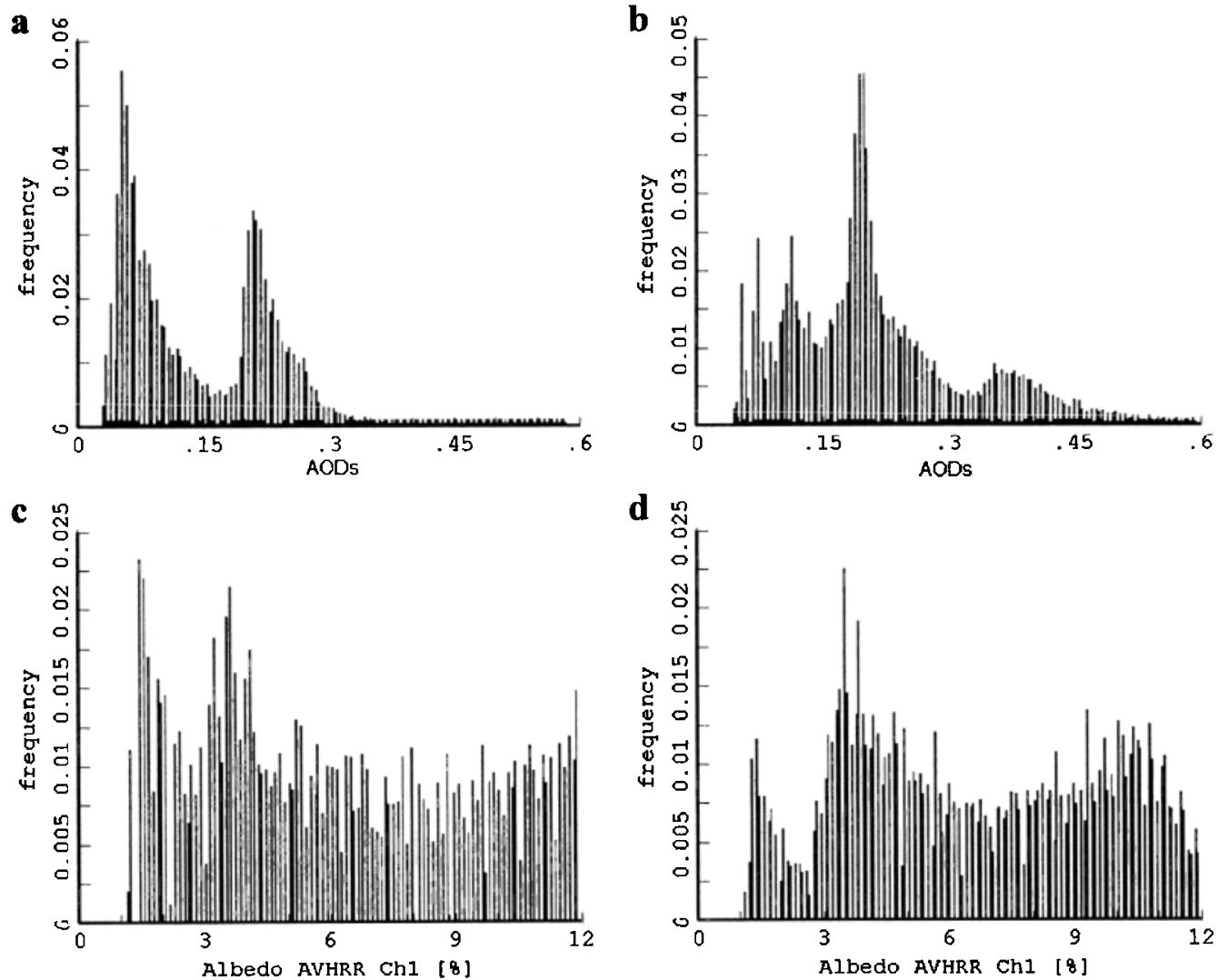

Figure 6. Histograms of $\mathrm{AOD}_{S}$ for a typical day without dust outbreak over the Atlantic Ocean: (a) natural day 178 , and for a Saharan dust outbreak, (b) natural day 189. Histograms of AVHRR channel 1 albedo for the same days: (c) natural day 178, and (d) natural day 189.

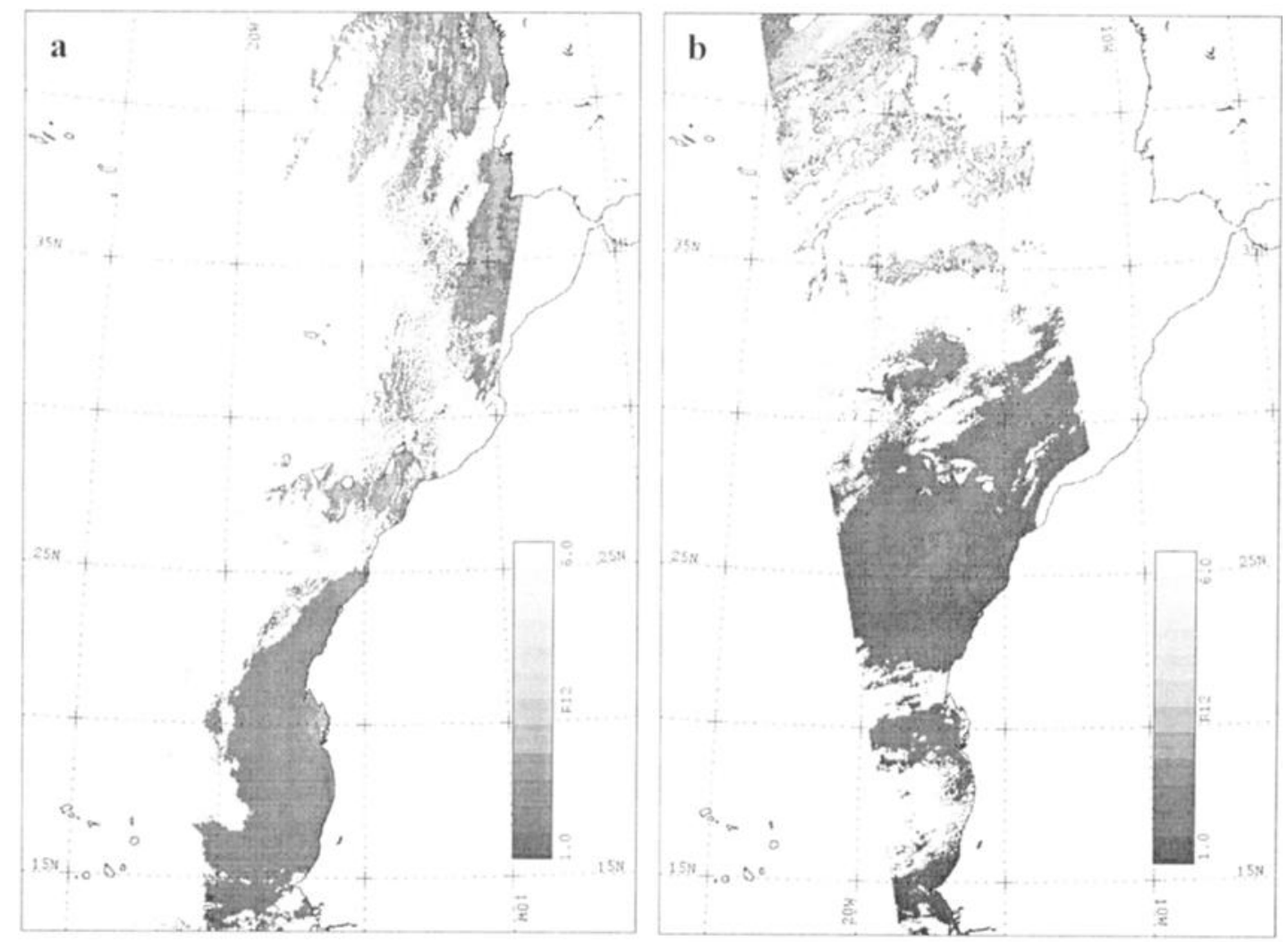

Figure 7. Ratio of the NOAA AVHRR channel $1(630 \mathrm{~nm})$ to channel $2(830 \mathrm{~nm}), R_{12}$, for a clean day: (a) natural day 178 , and dusty day (b) natural day 189 . White dots are clouds or bad data. 


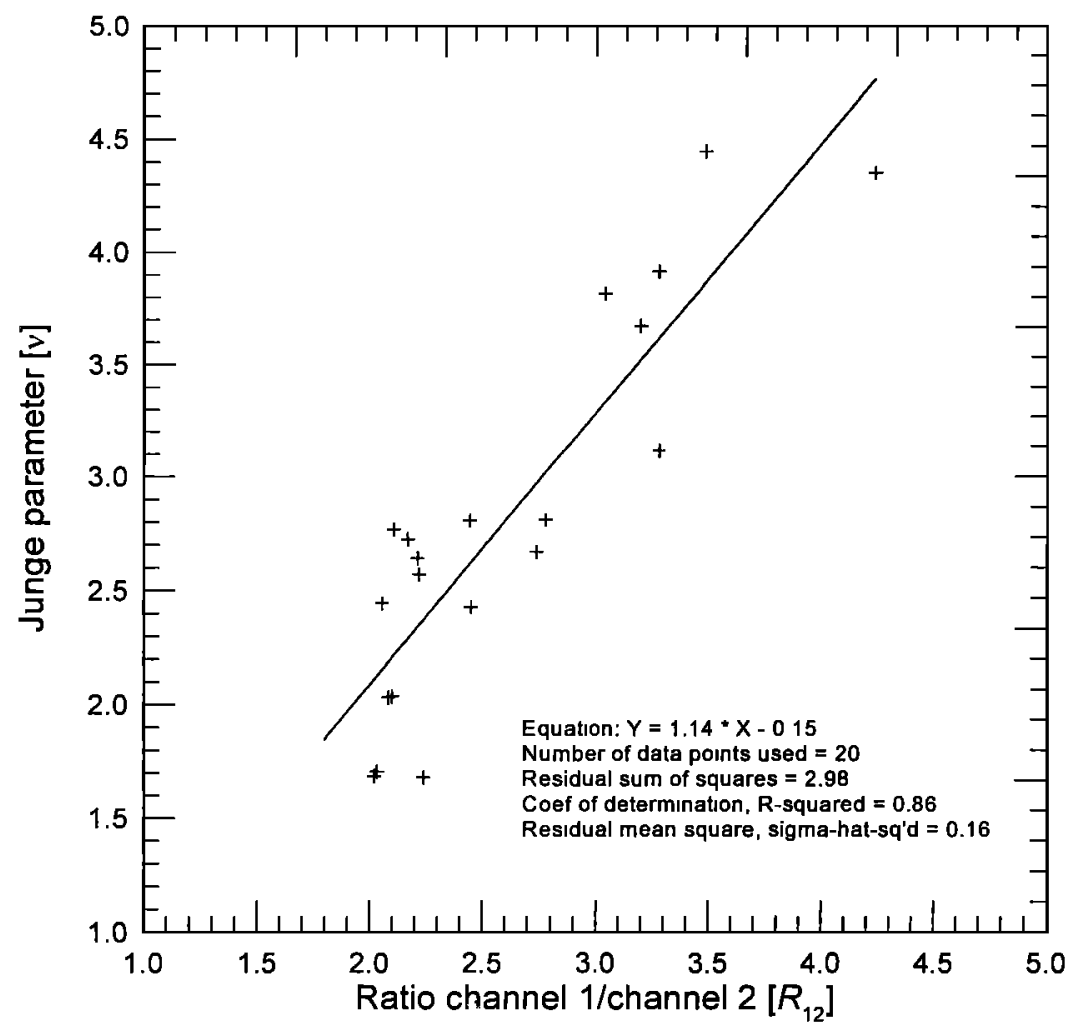

Figure 8. Junge size parameter (v) versus the ratio NOAA channel $1 /$ channel $2\left(R_{12}\right)$.

$$
\begin{gathered}
\tau(\lambda)=\int_{0}^{\infty} \pi r^{2} Q_{\mathrm{ext}}(\lambda, r, m) n(r) d r, \\
g=\frac{\int_{0}^{\infty} \pi r^{2} Q_{\mathrm{sct}}(\lambda, r, m) g^{\prime}(\lambda, r, m) n(r) d r}{\int_{0}^{\infty} \pi r^{2} Q_{\mathrm{sct}}(\lambda, r, m) n(r) d r}, \\
\omega=\frac{\int_{0}^{\infty} \pi r^{2} Q_{\mathrm{sct}}(\lambda, r, m) n(r) d r}{\int_{0}^{\infty} \pi r^{2} Q_{\mathrm{ext}}(\lambda, r, m) n(r) d r},
\end{gathered}
$$

where $r$ is the aerosol particle radius, $\lambda$ is the wavelength, $m$ is the refraction index, $Q_{\text {sct }}(\lambda, r, m)$ and $Q_{\text {ext }}(\lambda, r, m)$ are the scattering and extinction coefficients, and $n(r)$ is the aerosol size distribution. The parameter $g^{\prime}$ is the asymmetry factor for a particle of radius $r$ and complex index of refraction $m$.

Both $Q_{\text {stt }}(\lambda, r, m)$ and $Q_{\text {ext }}(\lambda, r, m)$ have been evaluated using the Mie scattering theory. We have used the algorithm given by Wiscombe [1979], which has an accuracy of at least six significant digits. Also, the asymmetry factor $\left(g^{\prime}\right)$ for a particle of radius $r$ and complex index of refraction $m$ was evaluated by the same algorithm. For the dust complex index of refraction we use the value $1.560-0.006 i$ [Patterson et al., 1977].

Different authors have studied the possible invalidity of Mie theory due to the nonsphericity of the particles [Mishchenko et al., 1997; West et al., 1997; Kahn et al., 1997]. They have established that the differences between spherical and nonspherical particles are especially small in the single-scattering albedo for a size parameter greater than 1 . For size parameters greater than 2 these errors do not exceed $2 \%$. On the other hand, the differences to the asymmetry factor are less than $7 \%$ for the size parameter range from 0 to 30 and less than $3.5 \%$ for size parameters larger than 7 . Anyway, the results found by Mishchenko et al. [1997], Lacis and Mishchenko [1995], and Mishchenko et al. [1995] suggest that the influence of the particle shape in the aerosol radiative forcing can be considered negligibly small. Thus they can be accurately computed using the Mie theory if the AOD is already known.

The particle size distribution $n(r)$ has been obtained using the constrained linear inversion method of King et al. [1978]. This parameter can be related with the measured $A O D, \tau_{A}$, using the Mie-scattering approximation by equation (7).

As noted by King et al. [1978], this problem is ill-posed and the size distributions inverted from extinction spectra are nonunique. Several authors have tested the inversion calculations by varying the refraction index, the size distribution, the number of iterations, etc., and they have estimated the error in the aerosol radiative properties computed from these size distributions [King et al., 1978; Heintzenberg et al., 1981; González-Jorge and Ogren, 1996]. The studies show that if the refraction index $(m)$ is known, the estimated error for the asymmetry factor $g$ is less than $4 \%$; on the other hand, if $m$ is not known exactly, the error can increase up to $7 \%$. Following the King's inversion method the particle radii range, for which the aerosol size distribution will be obtained, must be chosen properly in order to avoid problems with the convergence of the method. This radii interval is determined by Heintzenberg et al. [1981] criteria, which establishes that a radii interval is valid if the ratios between the extinction efficiency factor at different used wavelengths depend on the particle radii. When this occurs the aerosol optical depth data measured at the used wavelengths have independence information in this finite radii range.

We have estimated the $g$ and $\omega$ errors due to our implementation of the method to calculate the radiative properties of the mineral dust. For it we have supposed a 

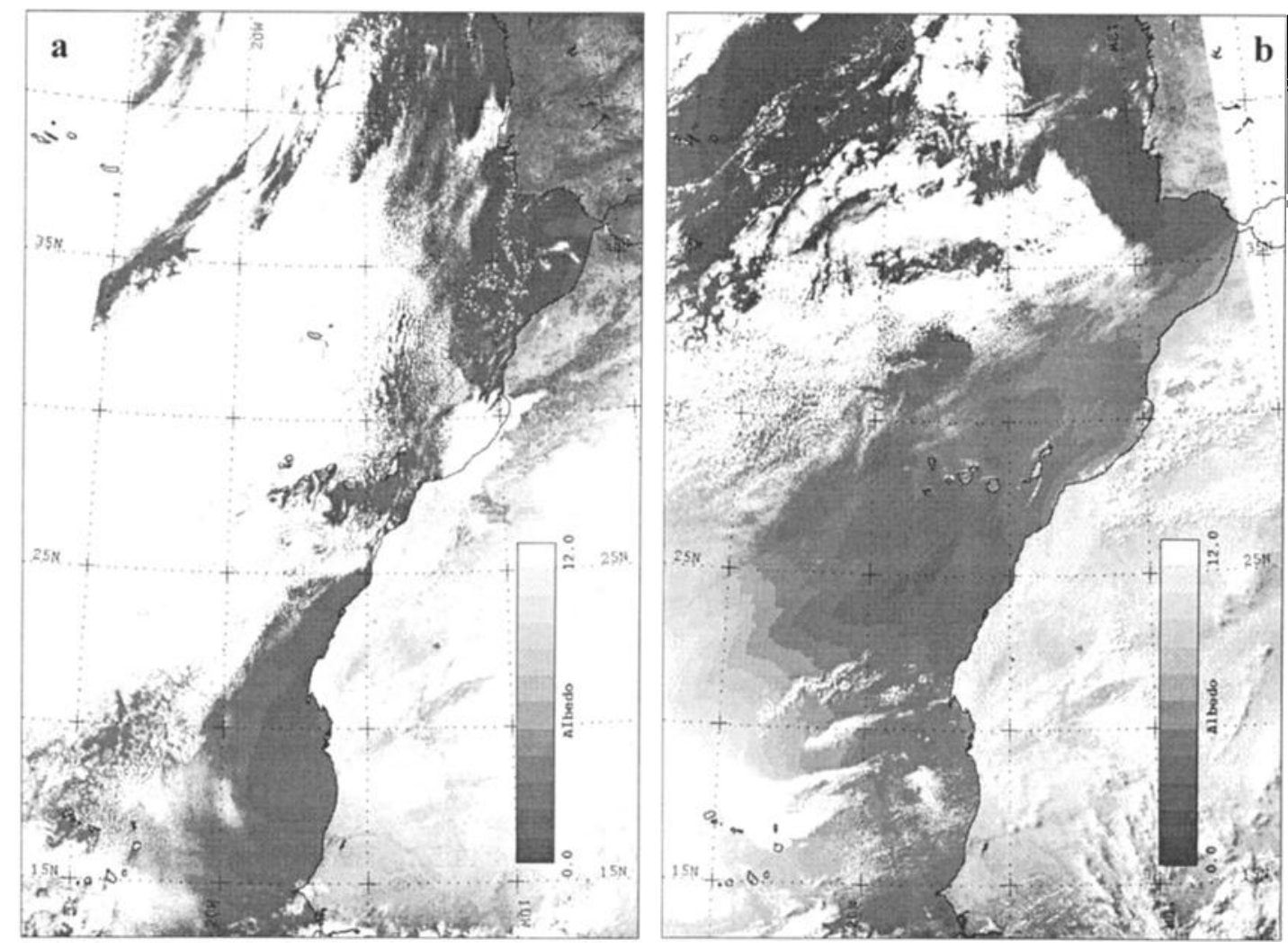

Figure 9. Albedo for a typical day without dust outbreak over the Atlantic Ocean: (a) natural day 178, and for a Saharan dust outbreak (b) natural day 189 . White dots are clouds or bad data.

maritime atmosphere, i.e., from 0 up to $2 \mathrm{~km}$ height, a maritime aerosol type; $2-12 \mathrm{~km}$ a continental aerosol type; $12-30 \mathrm{~km}$ a background stratospheric aerosol model and above $30 \mathrm{~km}$ an upper atmospheric aerosol model [WCRP, 1986]. We have added mineral dust between sea level and $6 \mathrm{~km}$ height. The mineral dust size distribution within each layer has been modeled by a lognormal size distribution. We note as "real" size distribution the integration in height of this vertical composition. The AOD of this total column aerosol size distribution has been computed via Mie-scattering theory. These AOD values have been used as input to the King's inversion method to obtain a "modeled" aerosol size distribution. The errors in the radiative properties have been obtained comparing the $g$ and $\omega$ computed for the "real" size distribution versus the calculated for the "modeled" one. In Table 1 we show the error in percent for two situations: the first one $(\tau=0.2)$ corresponds
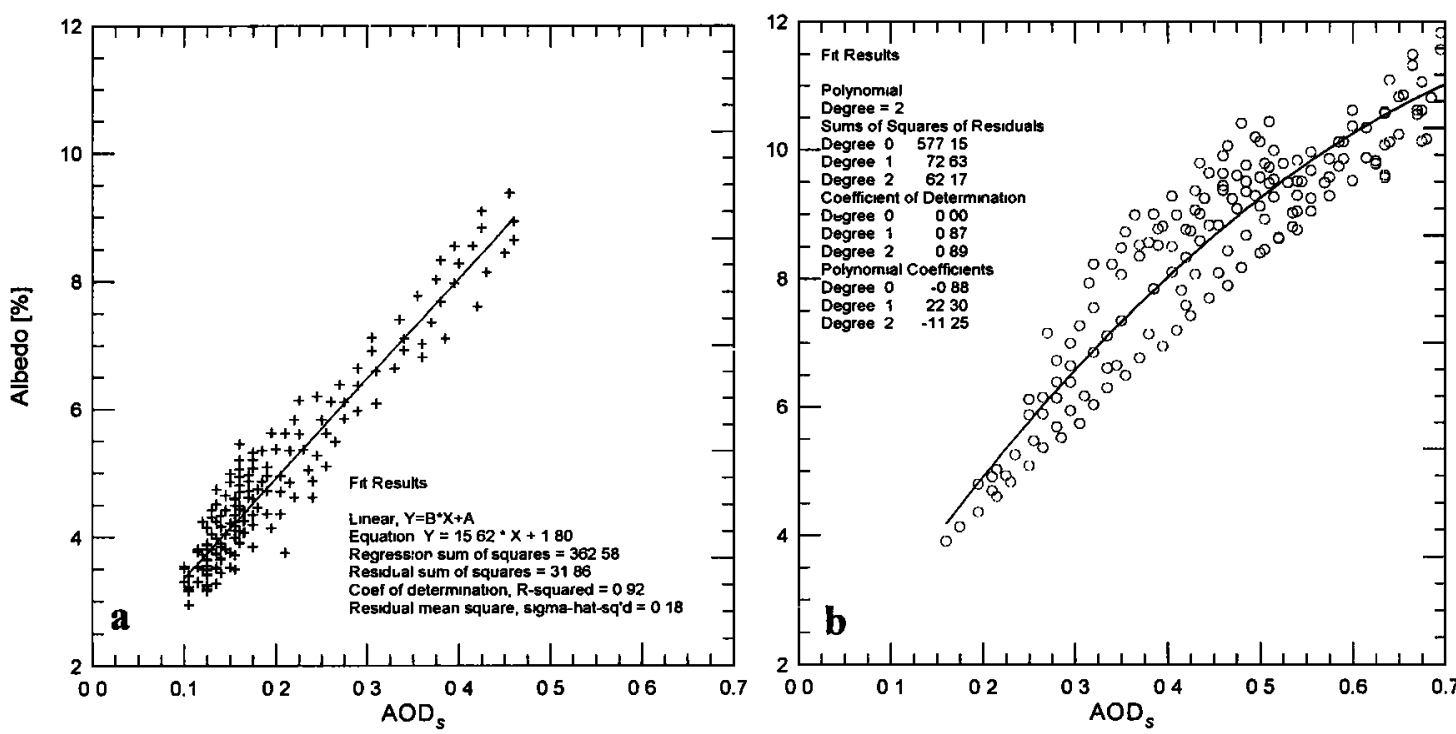

Figure 10. Albedo versus $A O D_{s}$ for a typical day: (a) without dust outbreak over the Atlantic Ocean, natural day 178; (b) for a Saharan dust outbreak, natural day 189. 
Table 1. Estimated Error in $g$ and $\omega$ for a Maritime Size Distribution

\begin{tabular}{ccc}
\hline$\lambda=500 \mathrm{~nm}$ & Error $g(\%)$ & Error $\omega(\%)$ \\
\hline$m=1.56-0.006 i$ & & \\
$\tau=0.2$ & 6.46 & 2.25 \\
$\tau=0.5$ & 466 & 14.80 \\
$m=1.55-0.005 i$ & & \\
$\tau=0.2$ & 5.92 & 2.25 \\
$\tau=0.5$ & 494 & 19.13 \\
$m=1.53-0.023 i$ & & \\
$\tau=0.2$ & 2.90 & 16.58 \\
$\tau=0.5$ & 4.05 & 11.19 \\
\hline
\end{tabular}

to a case without dust, whereas in the second one $(\tau=0.5)$, the dust has been distributed as mentioned above. These calculations have been done using three refractive indexes in King's algorithm.

Taking into account the different error sources indicated the overall uncertainties (root-square-sum) in $g$ and $\omega$ are $10 \%$ and $13 \%$, respectively.

We computed the aerosol size distributions for all dusty days. Days were selected on the basis of Figures 2, 3, and 5 and visual observations, which indicated that the ground station was affected by dust. They were $162,163,180,181,182,183,184$, $185,186,190,191,192,195,196,202,203,204,205,221$, and 222. Applying equations (8) and (9), we obtain $g(\lambda)$ and $\omega(\lambda)$ values for all dusty days at wavelengths from 0.2 to $4.0 \mu \mathrm{m}$. Figure 11 shows the average values of these parameters versus wavelength for all dusty days. The $\omega$ and $g$ values at $500 \mathrm{~nm}$ are $\omega=0.87$ and $g=0.83$. These values are consistent (in magnitude and in their wavelength dependence) with those computed for mineral dust by several authors. Sokolik and Toon [1996] obtained for $\omega(500 \mathrm{~nm})$ a value of 0.85 and for $\mathrm{g} 0.75$. Sokolik and Golitsyn [1993] found that for the wavelength range from 0.3 to $3 \mu \mathrm{m}, \omega$ varied between 0.72 and 0.94 and $g$ between 0.84 and 0.68. Sokolik and Toon [1996] obtained (for the wavelength range from 0.3 to $2 \mu \mathrm{m}$ ) a value of $\omega$ in the range 0.62 and 0.96 , and for $g 0.84$ and 0.64 . For aerosol particles produced by biomass burning, Penner et al. [1992] report values for $\omega$ in the range 0.80 and 0.95 , depending on the environmental conditions. The solar local mean AOD computed by the aerosol size distribution obtained during dusty days and using equation (7) is $\tau=0.27$.

\section{Discussion and Conclusions}

Some authors have pointed out the importance of studying mineral dust due to its significant role in the scattering of light. Theoretical and experimental studies have shown that the effect of this atmospheric component in the radiation budget is comparable to the greenhouse effect gases but opposite in sign. Moreover, the spatial and temporal variations shown in their physical properties make necessary a major effort not only on a planetary scale but also on a regional scale.

In this paper we report on a series of surface-based measurements of $\mathrm{AT}_{T}$ and $\mathrm{AOD}_{T}$ at three wavelengths, 368, 500 , and $778 \mathrm{~nm}$, made on Tenerife and NOAA AVHRR channel 1 measurements of albedo and $\mathrm{AOD}_{s}$. We show that large changes occur in these variables when Saharan dust outbreaks enter the region. $\mathrm{AOD}_{T}$ values at $500 \mathrm{~nm}$ can increase from 0.05 , a value that is typical for dust-free conditions, to 0.3 in a matter of a few hours after the dust front arrives at Tenerife. Large changes were also measured in the $\mathrm{AOD}_{S}$ and albedo NOAA channel 1. Close to the coast of West Africa, albedo values, which are typically about $3 \%$, can increase to $10 \%$; similarly, $\mathrm{AOD}_{S}$ ranges from 0.06 in clear zones to values as high as 0.6 when a Saharan dust outbreak occurs. The albedo data can be fitted by linear regression to $A O D_{s}$ data up to values of about 0.5 .

Aerosol measurements made in the free troposphere at Izaña Observatory $(2360 \mathrm{~m})$ and in the marine boundary layer at Punta del Hidalgo show that Saharan dust concentrations at Izaña are much greater than those measured at $\mathrm{PDH}$. Furthermore, during dust outbreaks the concentration of dust is tens of times greater than other aerosol species. The importance of the dust in radiative processes is emphasized by that fact that the $\mathrm{AOD}_{T}$ measurements closely track the concentrations of mineral dust. Also, we clearly observe from satellite images that when we detect Saharan mineral dust outbreaks, radiative magnitudes, such as albedo, $\mathrm{AOD}_{S}$, or $R_{12}$, are mainly determined by the concentrations of this aerosol specie.

The single-scattering albedo $(\omega)$ and the asymmetry factor $(g)$ were evaluated at the solar wavelengths from aerosol size
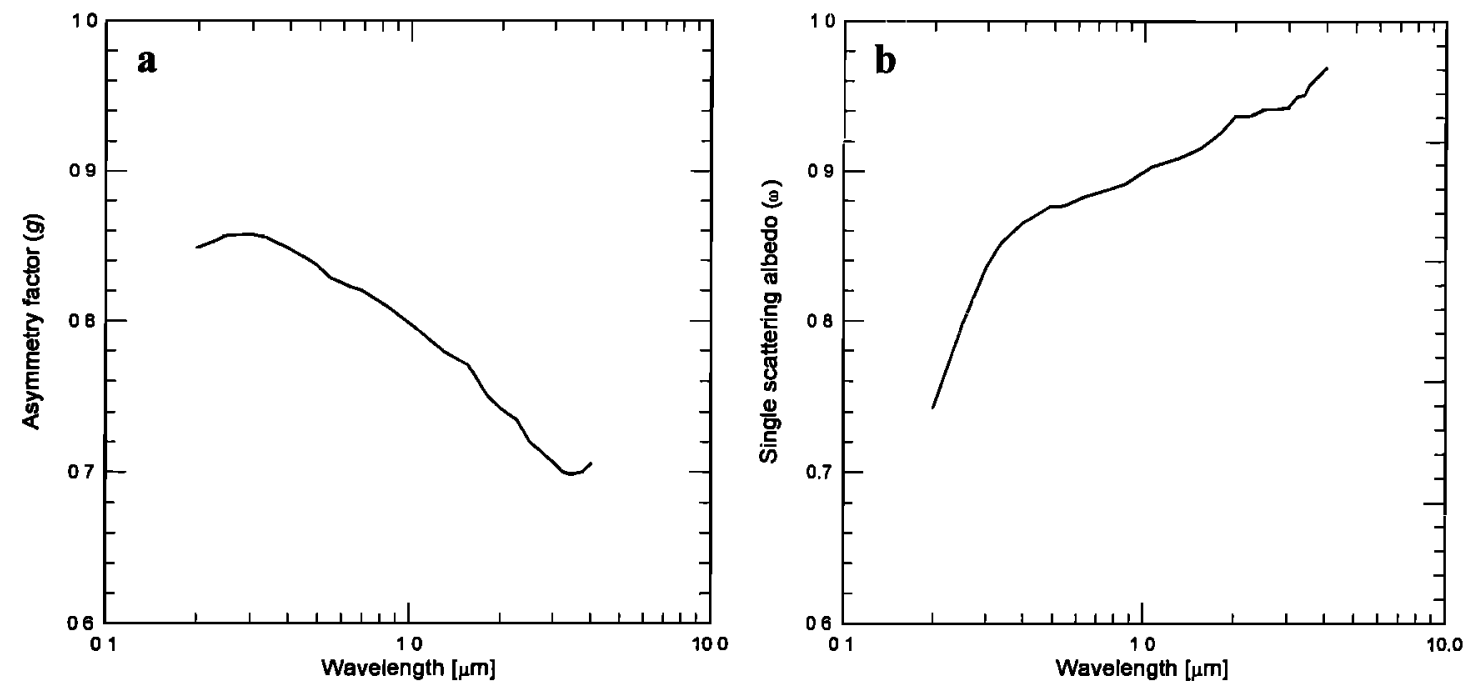

Figure 11. (a) Asymmetry factor ( $g$ ) averaged for all dusty days versus $\lambda$; (b) the single scattering albedo $(\omega)$ averaged for all dusty days versus $\lambda$. 
distributions obtained by the King's inversion method. These measurements are the first to be made directly on mineral dust in Tenerife, using the technique reported here. Also, the consistency of our results over the period of the experiment shows that these values are relatively constant from event to event. The standard deviation ( $\sigma$ ) of the $g$ and $\omega$ values to the whole period are $\sigma(g)= \pm 0.08(10 \%)$ and $\sigma(\omega)= \pm 0.03(4 \%)$. Our results also narrow the range of the previous estimates of these parameters.

With the $\omega, g$, and local mean AOD values obtained in this work, we obtain a mean value for the local mineral dust radiative forcing over the ocean $\Delta F=-9.7 \mathrm{~W} / \mathrm{m}^{2}$ and for the land $\Delta F=-4.5 \mathrm{~W} / \mathrm{m}^{2}$. Using Tegen et al. [1996] estimates of global mean AOD, the values for global mean forcing for the mineral dust are $\Delta F=-1.22 \mathrm{~W} / \mathrm{m}^{2}$ over the ocean and $\Delta F=-0.57 \mathrm{~W} / \mathrm{m}^{2}$ for the land. The error in $\Delta F$, calculated by the error propagation technique, due to the uncertainties in $\tau, g$, and $\omega$ has been estimated to be $\pm 25 \%$ over ocean and $\pm 25 \%$ over land. The values obtained by us for forcing by dust are comparable to results obtained by others using different approaches. Tegen et al. [1996] propose a value of $-1 \mathrm{~W} / \mathrm{m}^{2}$; Sokolik and Toon [1996] estimate dust forcing to be $-0.25 \mathrm{~W} / \mathrm{m}^{2}$ over land and $-0.6 \mathrm{~W} / \mathrm{m}^{2}$ over ocean. These various estimates of forcing by mineral dust are comparable to estimates of forcing by other types of aerosols. For anthropogenic sulfate, Kiehl and Briegleb [1993] and Taylor and Penner [1994] suggest a globally averaged direct radiative forcing in the range -0.3 and $-0.9 \mathrm{~W} / \mathrm{m}^{2}$. For biomass burning aerosols, Penner et al. [1992] estimate this effect on about $-1 \mathrm{~W} / \mathrm{m}^{2}$. Thus it is clear from our analysis that the forcing attributable to mineral dust is comparable to that attributed to aerosols from other types of sources.

Because of the different spatial-temporal characteristics and physical-chemical properties of the different aerosol species (natural and anthropogenic) it is very complicated to obtain an average image of the radiative role of the aerosols in a global scale. Because of the geographical dimensions of the problem the use of satellites is necessary. These space measurements must be completed with a ground-based network to do the intercomparison with the satellite measurements in order to get the necessary accuracy and precision. To obtain this, the space platform must be equipped with a spectral instrument to measure radiative properties such as $g$ and $\omega$, both over land and oceans. We hope that this task can be obtained with actual and future satellites as ADEOS-POLDER, Seastar-SeaWiFS, Envisat-Meris, Envisat-AATSR, Envisat-SCIAMACHY, EOSMODIS, EOS-MISR, etc. On the other hand, unfortunately, there is a lack of instrumentation designed specifically to profile aerosols in the near future. For this task new techniques are necessary, such as space-borne lidars, whose implementation has not yet been planned.

Acknowledgments. We wish to thank the Gobierno Autónomo de Canarias for its financial support by contract $4 / 95$, the Comısión Interministerial de Ciencia y Tecnologia (CICYT) by contract CLI970453 , and the University of La Laguna by contract 1802260003 . A portion of this work was carried out as part of the Atmosphere/Ocean Chemistry Experiment (AEROCE) and supported by the National Science Foundation grants ATM-9414808, ATM-9414812, and ATM9414846.

\section{References}

Andreae, M.O., Raising dust in the greenhouse, Nature, 380, 389-390, 1996.

Arimoto, R., R. A Duce, B. J Ray, W. G Ellis Jr., J. D Cullen, and J.
T. Merrill, Trace elements in the atmosphere over the North Atlantic, J. Geophys. Res., I00, 1199-1213, 1995.

Bergametti, G., L. Gomes, G Coude-Gausseu, P. Rognon, M.N. Le Coustumer, Saharan dust observed over Canary Islands: Source regions identification and transport pattern for some summer situations, J. Geophys Res., 94, 14,855-14,864, 1989.

Box, M. A., and A Deepak, Atmospheric scattering corrections to solar radiometry, Appl Opt., 12, 1941-1949, 1979.

Charlson, R.J., S.E. Schwartz, J.M. Hales, R.D. Cess, J.A. Coakley Jr. J.E. Hansen, and D.J. Hofmann, Climate forcing by anthropogenic aerosols, Science, 255, 423-430, 1992

Chiapello, I., Les aérosols atmosphériques au-dessus de l'Atlantique nord tropical: Approche physico-chimique et météorologique, Evaluation de la contribution des différentes espèces a l'épaisseur optique en aérosol, Ph.D thesis, 250 pp., Univ. Parıs, Paris, 1996.

Chiapello, I., G Bergamettı, L. Gomes, B. Chatenet, F. Dulac, J. Pimenta, and E. Santos Soares, An additional low layer transport of Sahelian and Saharan dust over the northeastern Tropical Atlantic, Geophys. Res. Lett., 22, 3191-3194, 1995.

Chylek, P., and J. Wong, Effect of absorbing aerosols on global radiation budget, Geophys. Res. Lett., 22, 929-931, 1995.

Diaz, J.P., F.J. Expósito, and A. Diaz, Measurements of aerosols from Tenerife, in Air Pollution '94, edited by J.M. Baldasano, C.A. Brebbia, H Power, and P. Zannetti, pp. 400-408, Comput. Mech. Publ., Southampton, England, 1994.

Diaz, J.P., F.J. Expósito, C.J. Torres, V. Carreño, and A. Redondas, Simulations of the mineral dust effect on the UV radiation levels, $J$. Geophys. Res., 105, 4979-4991, 2000.

Durkee, P.A., D.R. Jensen, E.E Hindman, and T.H. Vonder Haar, The relationship between marine aerosol particles and satellite-detected radiance, J. Geophys Res., 91, 4063-4072, 1986.

Dutton, E. G., R. Patrick, S. Ryan, and J. J. DeLuisi, Features and effects of aerosol optical depth observed at Mauna Loa, Hawaii: 1982-1992, J. Geophys. Res., 99, 8295-8306, 1994

Expósito, F.J., J.P. Díaz, M. Arbelo, F. Herrera, and A. Díaz, Comparison between the aerosols optical depth data obtained by the NOAA satellites and the Optronic OL752 spectroradiometer, in Sensors and Environmental Applications of Remote Sensing, edited by J Askne, pp. 333-336, A.A. Balkema, Brookfield, Vt., 1995.

Expósito, F J., J.P. Díaz, M. Arbelo, F. Herrera, and J.C. Guerra, First intercomparison between the AOD data obtained by the NOAA satellites and the Optronic OL752 spectroradiometer in the Canary Islands, Int. J. Remote Sens , I8(10), 2247-2252, 1997.

Frost, E.M., Global scale estimation of aerosol particle characteristics, Ph D. dissertation, Nav. Postgrad. Sch., Monterey, Calif., 1988.

Frulla, L.A., J.A. Milovich, and D.A. Gagliardini, Illumination and observation geometry for NOAA-AVHRR images, Int. J. Remote Sens., 16, 2233-2253, 1995.

González-Jorge, H., and J. Ogren, Sensitivity of retrieved aerosol properties to assumptions in the inversion of spectral optical depths, J. Atmos. Scr., 53, 3669-3683, 1996.

Heintzenberg, J., H. Müller, H. Quenzel, and E. Thomalla, Information content of optical data with respect to aerosol properties. Numerical studies with a randomized minimization-search-technique inversion algorithm, Appl Opt., 20(8), 1308-1315, 1981.

Herman, B.M, M.A. Box, J. Reagan, and C.M. Evans, Alternate approach to the analysis of solar photometer data, Appl. Opt., 20(17), 2925-2928, 1981

Herman, J.R., P.K. Bhartia, O. Torres, C. Hsu, C. Seftor, and E. Celarier, Global distribution of UV-absorbing aerosol from Nimbus7/TOMS data, J. Geophys. Res., 102, 16,911-16,922, 1997.

Husar, R.B., L.L. Stowe, and J.M. Prospero, Characterization of tropospheric aerosols over the oceans with the NOAA AVHRR optical thickness operational product, J. Geophys. Res., 102, 16,889$16,909,1997$.

Ignatov, A.M., L.L. Stowe, S.M. Sakerin, and G.K. Korotaev, Validation of the NOAA/NESDIS satellite aerosol product over the North Atlantic in 1989, J. Geophys. Res., 100, 5123-5132, 1995.

Ignatov, A., L Stowe, and R. Singh, Sensitivity study of the Angström exponent derived from AVHRR over the oceans, Adv. Space Res., $2 I(3), 439-442,1998$.

Iqbal, M., An Introduction to Solar Radiation, Academic, San Diego, Calif., 1983

Kahn, R., R. West, D. McDonald, and B. Rheingans, Sensitivity of multiangle remote sensing observations to aerosol sphericity, $J$. Geophys. Res., I02, 16,861-16,870, 1997

Karyampudi, M.V., S.P. Palm, J.A. Reagan, H. Fang, W.B. Grant, R.M Hoff, C. Moulin, H.F. Pierce, O. Torres, E.V. Browell, and S.H. 
Melfi, Validation of the Saharan dust plume conceptual model using lidar, Meteosat, and ECMWF data, Bull Amer Meteorol. Soc., 80(6), 1045-1076, 1999.

Kidwell, K.B., NOAA Polar Orbital Data User Guide, NOAA NESDIS, Nat. Clim. Data Cent., Satell. Data Serv. Div., Washington, D. C, 1995.

Kiehl, J.T., and B.P. Briegleb, The relative roles of surface aerosol and greenhouse gases in climate forcing, Scrence, 260, $311-314,1993$.

King, M.D., D.M. Byrne, B.M. Herman, and J.A Reagan, Aerosol size distributions obtained by inversion of spectral optical depth measurements, J. Atmos. Scl., 35, 2153-2167, 1978.

Lacis, A. A., and M. I. Mishchenko, Climate forcing, climate sensitivity and climate response: A radiative modeling perspective on atmospheric aerosols, in Aerosol Forcing of Climate, edited by $\mathbf{R} \mathbf{J}$ Charlson and J. Heitzenberg, pp. 11-42, John Wiley, New York 1995.

Laine, V., Atmospheric aerosol optical thickness and size distribution from satellite data over the Baltic Sea, Comm. Phys. Math. Chem. Med., 137, 1-95, 1992.

Li, X., H. Maring, D. Savoie, K. Voss, and J.M Prospero, Dominance of mineral dust in aerosol light-scattering in the North Atlantic trade winds, Nature, 380, 416-419, 1996.

Maring, H., D. Savoie, M. Izaguirre, C. McCormick, R. Arimoto, J. Prospero, and C. Pilinis, Aerosol physical and optical properties and their relationship to aerosol composition in the free troposphere at Izaña, Tenerife, Canary Islands during July 1995, J. Geophys Res., $105,14,677-14,700,2000$

Mishchenko, M. I., A. A. Lacis, B. E. Carison, and L. D. Travis, Nonsphericity of dust-like tropospheric aerosols: Implications for aerosol remote sensing and climate modeling, Geophys. Res Lett., 22, 1077-1080, 1995

Mishchenko, M. I., L. D. Travis, R. A. Kahn, and R. A. West, Modeling phase functions for dust-like tropospherıc aerosols using a shape mixture of randomly oriented polydisperse spheroids, J. Geophys. Res., 102, 16,831-16,847, 1997

Moulin, C., F. Guillard, F. Dulac, and C.E Lambert, Long-term daily monitoring of Saharan dust load over ocean using Meteosat ISCCPB2 data, 1, Methodology and preliminary results for 1983-1994 in the Mediterranean, J. Geophys. Res, I02, 16,947-16,958, 1997a.

Moulin, C., F. Dulac, C Lambert, P Chazette, I. Jankowiak, B. Chatenet, and F. Lavenu, Long-term daily monitoring of Saharan dust load over ocean using Meteosat ISCCP-B2 data, 2, Accuracy of the method and validation using Sun photometer measurements, $J$. Geophys. Res., 102, 16,959-16,969, $1997 \mathrm{~b}$.

Nakajima, T., and A. Hirigushi, AVHRR remote sensing of aerosols optical properties in the Persian Gulf region, summer 1991,J. Geophys. Res., 102, 16,935-16,946, 1997.

Patterson, E.M., D.A. Gillette, and B.H Stockton, Complex index of refraction between 300 and $700 \mathrm{~nm}$ for Saharan aerosols, J. Geophys. Res., 82, 3153-3160, 1977.

Penner, J.E., R.E. Dickinson, and C.A. O'Neill, Effects of aerosols from biomass buming on the global radiation budget, Science, 256 , 1432-1433, 1992.

Pinker, R.T., G. Idemudia, and T.O. Aro, Characteristic AOD during the Harmattan season on sub-Sahara Africa, Geophys. Res. Lett., $21(8), 685-688,1994$.

Porter, J.N., Measuring aerosol optical depth from satellite: Aerosol measurements and models, Ph.D. dissertation, Univ. of Hawaii, Honolulu, Hawaii, 1993.

Prospero, J.M., Saharan dust transport over the north Atlantic Ocean and Mediterranean An overview, in The Impact of Desert Dust Across the Mediterranean, edited by S. Guerzoni and R. Chester, pp. 133-151, Kluwer Acad., Norwell, Mass , 1996a.

Prospero, J.M., The atmospheric transport of particles to the ocean, in Particle Flux in the Ocean, edited by V Ittekkott, S. Honjo, and P.J. Depetris, pp. 19-52, SCOPE Rep. 57, John Wiley, New York, $1996 \mathrm{~b}$.

Pszenny, A., D. Fischer, A. Mendez, and M. Zetwo, Direct comparison of cellulose and quartz fiber filters for sampling submicrometer aerosols in the marine boundary layer, Atmos. Environ, 27 A, 281-284, 1993.

Raes, F., R. Van Dingenen, E. Cuevas, P.F J. Van Velthoven, and J.M. Prospero, Observations of aerosols in the free troposphere and marine boundary layer of the subtropical Northeast Atlantic: Discussion of processes determining their size distribution, $J$. Geophys. Res., 102, 21,315-21,328, 1997.
Rao, C.R.N., and J. Chen, Post-launch calibration of the visible and near-infrared channels of the Advanced Very High Resolution Radiometer on NOAA-7, -9 , and -11 spacecraft, NOAA Tech. Rep. NESDIS 78, U.S. Dep. of Comm., Washington, D. C., 1994.

Reagan, J. A., L. W. Thomason, B. M. Herman, and J M. Palmer, Assessment of atmospheric limitations on the determination of the solar spectral constant from the ground-based spectroradiometer measurements, IEEE Trans. Geoscr. Remote Sens., GE-24(2), 258266, 1986.

Russell, P. B., J.M. Livingston, E.G. Dutton, R F. Pueschel, J.A. Reagan, T.E. DeFoor, and M.A Box, Pinatubo and pre-Pinatubo optical depth spectra Mauna Loa measurements, comparisons, inferred particle size distributions, radiative effects, and relationship to lidar data, J. Geophys. Res., 98, 22,969-22,985, 1993.

Sancho, P, J. de la Cruz, A. Díaz, F. Martín, E. Hernández, F. Valero, and B. Albarrán, A five-year climatology of back-trajectories from the Izaña baseline station, Tenerıfe, Canary Islands, Atmos. Environ., 26A(6), 1081-1096, 1992.

Savoic, D. L., Nitrate and non-sea-salt sulfate aerosols over major regions of the world ocean: Concentration, sources and fluxes, Ph.D. thesis, 432 pp., Univ. of Miamı, Miami, Fl., 1984.

Sokolik, I.N., and G.S. Golitsyn, Investigation of optical and radiative properties of atmospheric dust aerosols, Atmos. Environ., 27 A, 2509. 2517, 1993.

Sokolik, I.N., and O.B. Toon, Direct radiative forcing by anthropogenic airborne mineral aerosols, Nature, 381, 681-683, 1996

Stowe, L. L., A. A. Ignatov, and R. R Singh, Development, validation and potential enhancements to the second generation operational aerosol product at NOAA/NESDIS, J. Geophys. Res., 102, 16,92316,934, 1997.

Swap, R., S. Ulanski, M. Cobbett, and M. Garstang, Temporal and spatial characteristics of Saharan dust outbreaks, J. Geophys. Res., $10 I, 4205-4220,1996$.

Taylor, K.E., and J.E. Penner, Response of climate system to atmospheric aerosols and greenhouse gases, Nature, 369, 734-737, 1994.

Tegen, I., A.A. Lacis, and I. Fung, The influence on climate forcing of mineral aerosols from disturbed soils, Nature, 380, 419-422, 1996

Thomason, L. W., B M Herman, and J. A. Reagan, The effect of atmospheric attenuators with structured vertical distributions on air mass determinations and Langley plot analyses, J. Atmos. Scl., 40, $1851-1854,1983$.

Tomasi, C., E. Caroli, and V. Vitale, Study of the relationship between Angström's wavelength exponent and Junge particle size distribution exponent, J. Clim. Appl. Meteorol, 22, 1707-1716, 1983.

West, R. A., L. R. Doose, A. M. Eibl, and M. G. Tomasko, Laboratory measurements of mineral dust scattering phase function and linear polarization, J. Geophys. Res., 102, 16,871-16,881, 1997.

Westphal, D.L., O.B. Toon, and T.N. Carlson, A case study of mobilization and transport of Saharan dust, J. Atmos. Sct., 45, 2145 $2175,1988$.

Wiscombe, W., Mie Scattering Calculations; Advances in Technique and Fast, Vector-Speed Computer Codes, U.S. Natl. Cent. for Atmos. Res., Boulder, Colo., 1979.

World Climate Research Program (WCRP), A preliminary cloudless atmosphere for radiation computation, WCP-112,WMO/TD-24, 55 pp., World Meteorol. Organ., Geneva, Switzerland, 1986.

Young, T.L., TeraScan Reference Manual, SeaSpace, San Diego, Calif,, 1992.

J.P. Díaz, F.J. Expósito, F. Herrera, and C.J. Torres, Department of Physics, University of La Laguna, A/Astrofísico Francisco Sánchez s/n, 38200 La Laguna, Santa Cruz de Tenerife, Canary Islands, Spain. (jpdiaz@ull.es)

J.M. Prospero, Rosenstiel School of Marine and Atmospheric Science, University of Miami, 4600 Rickenbacker Causeway, Miami, FL 33149

M.C. Romero, Instituto Nacional de Meteorologia, Izaña GAW Observatory, C/San Sebastián, 77, 38071 Santa Cruz de Tenerife, Canary Islands, Spain.

(Received March 2, 2000; revised January 2, 2001; accepted January 3, 2001.) 